Published in final edited form as:

Curr Urol Rep. 2015 May ; 16(5): 30. doi:10.1007/s11934-015-0505-y.

\title{
Lymph Node Staging in Prostate Cancer
}

\author{
Sandeep Sankineni, \\ Molecular Imaging Program, National Cancer Institute, National Institutes of Health, 10 Center \\ Drive, Building 10, Room B3B85, Bethesda, MD, USA
}

\section{Anna M. Brown,}

Molecular Imaging Program, National Cancer Institute, National Institutes of Health, 10 Center Drive, Building 10, Room B3B85, Bethesda, MD, USA

Duke University School of Medicine, Durham, NC, USA

Michele Fascelli, Urologic Oncology Branch, National Cancer Institute, National Institutes of Health, Bethesda, MD, USA

Sidney Kimmel Medical College, Thomas Jefferson University, Philadelphia, PA, USA

Yan Mee Law,

Department of Diagnostic Radiology, Singapore General Hospital, Singapore, Singapore

\author{
Peter A. Pinto, \\ Urologic Oncology Branch, National Cancer Institute, National Institutes of Health, Bethesda, MD, \\ USA
}

Peter L. Choyke, and

Molecular Imaging Program, National Cancer Institute, National Institutes of Health, 10 Center Drive, Building 10, Room B3B85, Bethesda, MD, USA

\section{Baris Turkbey}

Molecular Imaging Program, National Cancer Institute, National Institutes of Health, 10 Center Drive, Building 10, Room B3B85, Bethesda, MD, USA

\begin{abstract}
Nodal staging is important in prostate cancer treatment. While surgical lymph node dissection is the classic method of determining whether lymph nodes harbor malignancy, this is a very invasive technique. Current noninvasive approaches to identifying malignant lymph nodes are limited. Conventional imaging methods rely on size and morphology of lymph nodes and have notoriously low sensitivity for detecting malignant nodes. New imaging techniques such as targeted positron emission tomography (PET) imaging and magnetic resonance lymphography (MRL) with iron
\end{abstract}

Conflict of Interest Dr. Sandeep Sankineni, Dr. Anna M. Brown, Dr. Michele Fascelli, Dr. Yan Mee Law, Dr. Peter A. Pinto, Dr. Peter L. Choyke, and Dr. Baris Turkbey each declare no potential conflicts of interest.

Human and Animal Rights and Informed Consent This article does not contain any studies with human or animal subjects performed by any of the authors. 
oxide particles are promising for nodal staging of prostate cancer. In this review, the strengths and limitations of imaging techniques for lymph node staging of prostate cancer are discussed.

\section{Keywords}

Prostate cancer; Lymph node staging; Imaging

\section{Introduction}

Prostate cancer is a common human malignancy and the second leading cause of cancer death in American men [1]. When prostate cancer is confined to the gland, it has an excellent chance for cure. However, the presence of lymph node metastases portends a less favorable prognosis. Accurate lymph node (LN) staging is critical for treatment planning and therapy monitoring [2]. Lymph node involvement in prostate cancer is commonly treated initially with androgen deprivation therapy and radiation therapy to the pelvis. In patients with high-risk prostate cancer (serum prostate-specific antigen (PSA) > $20 \mathrm{ng} / \mathrm{dL}$, Gleason score $\geq 8$, or extra-prostatic spread), there is an increased risk of biochemical recurrence after definitive treatment due to local recurrence, nodal recurrence, or metastatic disease. [3]. Lymph node metastases can portend a poor prognosis, however, the 5-year survival rate depends on the total number of metastatic LNs ranging from a 5-year survival of 75-80 \% in patients with a single metastatic LN to only $20-30 \%$ in patients with more than five metastatic LNs [4]. Currently, surgical pelvic LN dissection with histo-pathological examination is the standard of care and the most commonly used method of LN staging. However, pelvic LN dissection can be a technically challenging and is associated with higher rates of complications such as lymphocele, deep venous thrombosis, pelvic hematoma, fever, and urinary retention that may result in longer hospital stays [5]. Moreover, once a lymph node dissection has been performed, it is difficult to reoperate on the same patient due to postoperative scarring. Nodes outside the normal resection template may also be missed and, hence, undersampled, at surgery. Thus, there is a need for accurate noninvasive imaging methods to accurately detect nodal disease. In this article, we will discuss traditional and novel noninvasive imaging techniques used for LN staging in prostate cancer.

\section{Conventional Computed Tomography (CT) and Magnetic Resonance Imaging (MRI)}

The conventional approach to LN staging in prostate cancer patients includes the use of contrast-enhanced CT and MRI. For both modalities, the definition of suspicious LNs is based mostly on size thresholds for enlarged LNs. The most commonly used threshold is 10 $\mathrm{mm}$ in short axis diameter [6]. However, recommended thresholds vary from 8 to $15 \mathrm{~mm}$ [710]. Lower thresholds have higher sensitivity but lower specificity, whereas higher thresholds have lower sensitivity and higher specificity, thus defining a receiver operator characteristic (ROC) curve. Attempts to standardize these thresholds have been made, such as with the Response Evaluation Criteria in Solid Tumors (RECIST) 1.1 criteria [11]. The RECIST criteria include guidelines for specific dimensions of LNs on CT. The updated 
version 1.1 states that LNs are normal if the short axis is $<10 \mathrm{~mm}$ and is a target lesion if the short axis is $>15 \mathrm{~mm}$ [12]. Using size criteria alone often leads to incorrect staging, however, due to the fact that smaller lymph nodes can commonly harbor microscopic foci malignancy $[8,13]$. Thus, in high-risk prostate cancer patients, conventional CT and MRI may underestimate LN stage $[14,15]$. A large review by Hovels et al. determined the pooled diagnostic accuracy of CT and MRI in determining LN status in patients with prostate cancer using RECIST criteria. The pooled sensitivity and specificity for CT were 0.42 (95\% CI 0.26-0.56) and 0.82 (95\% CI 0.80-0.83), respectively, compared to 0.39 (95\% CI $0.22-$ $0.56)$ and 0.82 (95\% CI 0.79-0.83) for MRI [15]. Most of the studies that were examined used only a limited, not extended, pelvic lymph node dissection to confirm imaging findings. Hovels et al. concluded that CT and MRI have limited ability to correctly identify malignant LNs, and, thus, should not be used for LN staging in prostate cancer patients. Their finding corroborates what many other studies in the literature have reported previously, that CT and MRI have poor sensitivity for LN detection [7, 16-18]. An imaging method incorporating both anatomical and functional information for accurate imaging of pelvic lymph nodes is needed for successful prostate cancer nodal staging.

There is some disagreement in the literature regarding the comparative performance of CT versus conventional MRI in LN staging in prostate cancer (Table 1). One large historical study indicated that CT and MRI are roughly equal in detecting malignant LNs as they use the same criteria [19]. This finding has been confirmed by a more recent study by Lecouvet et al. using whole body MRI including diffusion-weighted (DW-MRI) sequences [11]. The use of DW-MRI has been examined as an approach for staging independent of lymph node dissection techniques in prostate cancer patients. Budiharto and colleagues prospectively evaluated DW-MRI for LN staging and concluded that it was still inferior to extended lymph node dissection in determining lymph node status in prostate cancer patients [14]. Countering the supposition that $\mathrm{CT}$ and MRI are equivalently poor at LN staging, a recent study has shown MRI to be superior in the identification of the greatest number of suspicious LNs [6]. Saokar and colleagues postulated that MRI is a better method for LN identification compared to CT due to its improved soft tissue resolution and ability to distinguish LNs from vascular structures in the pelvis. They reported that differentiating nodes from vasculature was difficult on CT owing to inadequate opacification of small blood vessels in the pelvic region [6]. The results of this study correlated well with findings reported previously by Yang et al. that showed that MRI identified a greater number of pelvic LNs compared to CT in cervical cancer patients [20]. A major limitation of this study is the lack of tissue validation to determine malignancy status. This is of particular relevance since in their study MRI identified significantly more LNs with diameters of 1 to $5 \mathrm{~mm}$. While these would be classified as benign by common size thresholds and the RECIST 1.1 criteria, Saokar and colleagues complemented size criteria with imaging features like border appearance, mottled heterogeneous appearance, and signal intensity characteristics which are more subjective and qualitative, therefore, less likely to be reproducible across different observers [6]. These features have previously been reported to be helpful in evaluating LN metastases from rectal cancer on MRI [21, 22]. Recently, Thoeny et al. prospectively assessed the diagnostic performance of DW-MRI in the detection of pelvic lymph node metastases in patients with prostate and/or bladder cancer staged as N0 (no evidence of 
lymph node involvement) with other preoperative cross-sectional imaging. A total of 4846 lymph nodes were resected in 120 patients and 88 lymph node metastases were found in 33 of 120 patients ( $27.5 \%$ ). Short-axis diameter of these metastases was less than or equal to 3 $\mathrm{mm}$ in 68 , between $3-5 \mathrm{~mm}$ in 13 , between $5-8 \mathrm{~mm}$ in five, and between $8-10 \mathrm{~mm}$ in two nodes. On a per-patient level, the three readers in the study correctly detected metastases in 26 (79\%; $95 \%$ CI $64 \%, 91 \%), 21$ (64\%; $95 \%$ CI $45 \%, 79 \%)$, and 25 (76\%; $95 \%$ CI $60 \%, 90 \%$ ) of the 33 patients with metastases, with respective spec-ificities of $85 \%$ (95\% CI $78 \%, 92 \%), 79 \%$ (95\% CI $70 \%, 88 \%$ ), and $84 \%$ (95\% CI $76 \%, 92 \%)$. Nodal metastases were detected with histopathologic examination in 44 of 240 pelvic sides (18\%); the three readers correctly detected these on DW-MR images in $26(59 \% ; 95 \%$ CI $45 \%$, $73 \%), 19$ (43\%; $95 \%$ CI $27 \%, 57 \%$ ), and 28 (64\%; $95 \%$ CI $47 \%, 78 \%$ ) of the 44 cases. They concluded that DW-MRI enabled detection of small lymph node metastases in normalsized nodes in a substantial percentage of patients with prostate and bladder cancer diagnosed as N0 with conventional cross-sectional imaging techniques [23]. This combined approach of DW MRI with anatomic imaging has potential to obtain more accurate results for nodal staging than conventional CT and MRI especially in the presence of normal lymph nodes; however, these initial results need to be validated.

\section{Magnetic Resonance Lymphography with Ultrasmall Superparamagnetic Iron Oxide (USPIO)}

MR imaging can be improved by the use of contrast agents containing USPIO nanoparticles, which are taken up by subcapsular macrophages within LNs. The iron oxide within the USPIO turns normal lymph nodes dark on T2- and T2*-weighted MRI. This allows for the detection of early histological changes caused by microscopically infiltrating tumor cells, even before the LNs enlarge in size [24•]. The lympho-graphic properties of USPIOs have been known for over 15 years. In 1999 Harisinghani et al. (1999) investigated USPIO lymphography in 19 patients with primary abdominal and pelvic malignancies [25].

Several USPIOs have been suggested for human use. Initially, ferumoxtran-10, or Combidex, was the agent of choice. Ferumoxtran-10 was a biodegradable, dextran coated USPIO that exhibited, prolonged circulatory time and was avidly taken up by macrophages at relatively low iron doses of $2-4 \mathrm{mg} / \mathrm{kg}$. Once injected, ferumoxtran- 10 extravasates through capillary walls and is transported via the lymphatic system to the lymph node where it is phagocytized by macrophages [26]. In the presence of normal LN macrophages, feumoxtran-10 is taken up within $24 \mathrm{~h}$ resulting in reduced signal intensity and darkened lymph nodes. The iron oxide $\left(\mathrm{Fe}^{2+}\right.$ and $\left.\mathrm{Fe}^{3+}\right)$ core of ferumoxtran-10 strongly shortens the $\mathrm{T} 1, \mathrm{~T} 2$, and $\mathrm{T} 2 *$ of tissue turning normal nodes very dark. Over time, the particles disassociate and are metabolized with iron either entering the body's iron stores or being slowly eliminated via feces [27]. Lymph nodes that fail to take up ferumoxtran-10 remain either high or heterogeneous in signal intensity, suggesting possible metastasis. Metastases as small as 3-10 $\mathrm{mm}$ have been identified using ferumoxtran-10 imaging. Overall ferumoxtran-10 MR lymphography (MRL) demonstrates a high sensitivity $(\sim 90 \%)$ and specificity ( $95 \%$ ) for lymph node metastases in several malignancies including prostate 
cancer [26]. Unfortunately, ferumoxtran-10 was not pursued as a product by its manufacturer and is currently not widely available outside of The Netherlands.

Before it was discontinued, ferumoxtran-10 was used in a variety of studies with varying results. Traintafyllou et al. (2013) used extended pelvic lymph node dissection (ePLND) as a reference standard to detect lymph node metastases in prostate and bladder cancer patients with nodes smaller than $5 \mathrm{~mm}$ by using ferumoxtran-10-enhanced MRI at 3T and found positive and negative predictive values of 58.3 and $84.4 \%$ per patient respectively, suggesting that USPIO and MRI may aid in disease management but cannot be considered definitive [28]. This study is notable because of the small size of the nodes detected. This observation was confirmed by Birkhauser and colleagues, who showed that among 54 lymph nodes that were histologically confirmed for metastases, 47 (87\%) were smaller than $8 \mathrm{~mm}$ in their short axis, and of these, 38 (87\%) were successfully detected on combined ferumoxtran-10-enhanced MRL and diffusion-weighted MRI. The smallest subset of lymph nodes were smaller than $3 \mathrm{~mm}$, and MRL detected 14 of 16 (88\%) in this category [29].

Field strength may play a role in the success of USPIO MRL. Heesakkers et al. performed MRL in 48 prostate cancer patients at $3 \mathrm{~T}$ and showed significantly improved image quality for the higher field strength with improved nodal detection [30]. Harisinghani and colleagues conducted a study with ferumoxtran-10 in 80 patients with stage T1-3 prostate cancer. This study included 334 lymph nodes that were resected or biopsied. Of the 63 nodes with metastases detected by USPIO, 45 (71.4\%) did not fulfill the classic size or morphology criteria for malignancy. On a node-by-node basis, ferumoxtran-10 MRL had a significantly higher sensitivity than conventional MRI ( 90.5 vs. $35.4 \%, P<0.001)$ [24•]. Several authors have compared ferumoxtran-10 MRL with other imaging methods. For instance, Fortuin et al. compared ferumoxtran-10-enhanced MRL to ${ }^{11} \mathrm{C}$-choline PET/CT in prostate cancer patients, showing that MRL detected significantly more positive lymph nodes than PET/CT (151 metastases positive LNs in 23/29 patients vs. 34 metastases positive LNs in 13/29 patients for MRL vs. PET/CT, respectively) $(p<0.001)$ [31].

MRL with ferumoxtran-10 has several limitations, including the need to perform imaging pre-contrast and 24-36 $\mathrm{h}$ post-contrast due to the slow accumulation of the contrast agent within lymph nodes. Furthermore, the USPIO agent ferumoxtran-10 must be administered slowly through a filtered needle over 15-30 min to minimize infusion reactions including hypersensitivity and back pain. Approximately one fourth of patients participating in phase 3 clinical trials using ferumoxtran-10 reported headache, back pain, vasodilation, or urticaria as adverse events [32]. As mentioned, the agent is currently only available at one center in Europe on a research basis. Thus, there has been interest in other candidate USPIO agents with wider availability and better side effect profiles [32, 33].

Ferumoxytol was originally developed as an iron replacement therapy in chronic renal failure patients by the same company that developed ferumoxtran-10 [34-36]. Unlike fermoxtran-10, ferumoxytol is an FDA-approved semi-synthetic carbohydrate-coated magnetic iron oxide preparation that is administered as a bolus versus slow infusion with ferumoxtran-10 [35]. There is still limited clinical experience with ferumoxytol-enhanced MRI for metastatic lymph node mapping. One aspect of ferumoxytol that differs from 
ferumoxtran-10 is that it appears to have less affinity for macrophages, thus requiring higher doses. Harisinghani et al. reported using ferumoxytol in 10 prostate cancer patients at a dose of $4 \mathrm{mg} \mathrm{Fe} / \mathrm{kg}$ body weight (typical dose of ferumoxtran-10 is $2.6 \mathrm{mg} \mathrm{Fe} / \mathrm{kg}$ ). Among 26 nodes in 10 patients, ferumoxytol demonstrated a significant drop in the signal-to-noise ratio (SNR) in benign nodes, but little change in SNR within malignant nodes. Like ferumoxtran-10, ferumoxytol showed maximal reduction in node signal at $24 \mathrm{~h}$ after injection [37]. Turkbey and colleagues (2014) conducted a phase I dosing study of ferumoxytol to determine the optimal iron dose of this agent for MR lymphography [38]. Homogenous loss of signal in normal lymph nodes on MRI was consistently achieved at 7.5 $\mathrm{mg} \mathrm{Fe} / \mathrm{kg}$ [38]. This is considerably higher ( $\sim 3$ fold) iron dose compared with ferumoxtran-10. It should be noted that the recommended dose of ferumoxytol for iron replacement is $510 \mathrm{mg} \mathrm{Fe}$ (one vial) at day 1 with an additional $510 \mathrm{mg} \mathrm{Fe}$ vial 3-8 days later. This corresponds to $\sim 7.3 \mathrm{mg} \mathrm{Fe} / \mathrm{kg}$ for a $70 \mathrm{~kg}$ man. Thus, although the $7.5 \mathrm{mg} \mathrm{Fe} / \mathrm{kg}$ dose is higher than the recommended iron replacement dose for the first injection of ferumoxytol, the total dose is about the same as the recommended dose. The two phase injection strategy for ferumoxytol was implemented because ferumoxytol exhibits dosedependent, capacity-limited elimination from plasma with a half-life of approximately $15 \mathrm{~h}$ in humans and the clearance decreases with increasing doses of ferumoxytol [39]. The inconvenience of this regimen prompted a recent safety and efficacy study of 60 patients with iron deficiency anemia; 58 patients received a single-infusion dose of two vials of ferumoxytol totaling $1020 \mathrm{mg}$ ( $14.6 \mathrm{mg} \mathrm{Fe} / \mathrm{kg}$ in a $70 \mathrm{~kg}$ person) over $15 \mathrm{~min}$. Among the 58 patients, 2 failed to complete the dose due to an infusion reaction including cough, flushing, swollen lips, and pruritis, without hypotension, tachypnea, tachycardia, wheezing, stridor, or periorbital edema. Both patients recovered rapidly after treatment. Overall, 26 out of 60 (43.3\%) patients reported adverse events (AEs) of which 13 were mild and transient during infusion. Among the AEs, most common ones were self-limited arthralgias, myalgias, and/or headache within 24-48 h [40]. The safety data and the recent results from double dose studies implies that the clearance issue may be less of a problem for higher dose of ferumoxytol provided it is administered slowly. Further research is needed to continue to characterize the clinical applications of iron oxide nanoparticles as they relate to oncologic outcomes and clinical decision-making.

\section{Positron Emission Tomography (PET) CT}

The use of PET in combination with computed tomography (PET/CT) is established in the diagnosis, staging, restaging, and monitoring of tumor responses in many tumor types using FDG. However, the use of FDG in prostate cancer has been somewhat disappointing. Thus, a variety of different tracers have been developed for staging, assessment of biochemical recurrence $(\mathrm{BCR})$ in patients with treated prostate cancer and monitoring of metastatic castration-resistant prostate cancer (CRPC). The use of PET/CT in the assessment of local and regional pelvic lymph node (LN) metastases is commonly limited by high urinary bladder tracer activity of tracers excreted via the kidneys. In addition, due to limited resolution of PET/CT scanners $(4-5 \mathrm{~mm})$, sensitivity for small $(<5 \mathrm{~mm}) \mathrm{LN}$ metastases is low [41]. Currently employed radiotracers include the following: ${ }^{18} \mathrm{~F}-\mathrm{FDG},{ }^{18} \mathrm{~F}-$ and ${ }^{11} \mathrm{C}-$ 
choline compounds, prostate-specific membrane antigen (PSMA)-targeted tracers $\left({ }^{18} \mathrm{~F}\right.$ DCFBC), ${ }^{18}$ F-FDHT, ${ }^{18}$ F-FACBC, and ${ }^{11} \mathrm{C}$-acetate.

\section{${ }^{18} \mathrm{~F}$-Fluorodeoxyglucose $\left({ }^{18} \mathrm{~F}-\mathrm{FDG}\right)$}

The benefits of ${ }^{18} \mathrm{~F}$-FDG PET/CT in prostate cancer are limited, although it is successfully used to stage many other cancer types. The ability of ${ }^{18}$ F-FDG PET to detect cancer is based on the altered glucose metabolism in tumor cells and aerobic glycolysis in malignant tissue relative to normal tissue (Warburg effect). The limited use of ${ }^{18} \mathrm{~F}$-FDG PET/CT in prostate cancer has been attributed to the presumed low glucose metabolism rate and lower expression of glucose transporter 1 (GLUT-1) in prostate cancer. However, British researchers found GLUT-1 gene expression to be significantly higher in prostate cancer than in benign prostatic hyperplasia and that GLUT-1 gene expression correlated with Gleason score $[42,43]$. This may explain the observation of increased ${ }^{18}$ F-FDG uptake in CRPC.

${ }^{18}$ F-FDG PET can potentially be useful in detecting sites of biochemical recurrence (BCR). In a retrospective review of 91 patients with BCR after radical prostatectomy, PSA levels were higher in patients with FDG PET-positive findings than in patients with negative findings and a PSA of $2.4 \mathrm{ng} / \mathrm{mL}$ and PSA velocity of $1.3 \mathrm{ng} / \mathrm{mL} / \mathrm{y}$ provided the best tradeoff between sensitivity $(80 \% ; 71 \%)$ and specificity $(73 \% ; 77 \%)$ of FDG PET in a receiver operating curve analysis. Overall, ${ }^{18} \mathrm{~F}-\mathrm{FDG}$ PET detected local or systemic disease in $31 \%$ of patients with BCR [44]. It is important to note that ${ }^{18} \mathrm{~F}$-FDG is not specific for cancer, and false positive findings may occur in benign prostate hyperplasia (BPH) and inflammatory processes such as prostatitis or lymphadenitis [45].

\section{${ }^{11} \mathrm{C}$-Choline $/{ }^{18} \mathrm{~F}-\mathrm{Choline}$}

Radiolabeled choline accumulates in prostate tumors and choline and their extension to the lymph nodes [46]. Tumors exhibit upregulation of choline kinase, leading to increased trapping of choline in the form of phosphatidylcholine in the cell membrane. Choline can be labeled with ${ }^{18} \mathrm{~F}$ or ${ }^{11} \mathrm{C}$. Compared to FDG PET, ${ }^{11} \mathrm{C}$-choline has the advantage of minimal urinary excretion (it is excreted in the pancreas) and, therefore, minimal urinary bladder accumulation, allowing for improved detection of pelvic adenopathy. The disadvantage of ${ }^{11} \mathrm{C}$-cho-line is its short half-life of $20 \mathrm{~min}$ requiring an onsite cyclotron and radiochemistry facility for production. ${ }^{18} \mathrm{~F}$-choline has a longer half-life of $110 \mathrm{~min}$ and is therefore more easily provided by commercial sources (similar to ${ }^{18} \mathrm{~F}-\mathrm{FDG}$ ), but it has substantially more urinary excretion than ${ }^{11} \mathrm{C}$-choline limiting its use in the prostatic fossa.

PET/CT using ${ }^{11} \mathrm{C}$ or ${ }^{18} \mathrm{~F}$-labeled choline has been reported to have higher sensitivity and specificity than ${ }^{18} \mathrm{~F}-\mathrm{FDG}$ PET and has been investigated for staging and restaging of prostate cancer. In a study by Tilki et al. evaluating 1149 lymph nodes in 56 patients, ${ }^{18} \mathrm{~F}$-choline had a sensitivity and specificity of 40 and $96 \%$, respectively [47]. The sensitivity and specificity of ${ }^{18} \mathrm{~F}$-choline for detecting lymph node metastases in the primary staging of prostate carcinoma has been reported to be 19 to $80 \%$ and 82 to $98 \%$, respectively [48•]. This indicates a wide range of sensitivity likely due to the size of the lesions, but a consistently low false positive rate. 
The detection rate of malignant lymph nodes with choline PET improves with increasing size of lymph nodes. Choline PET is not sensitive for nodes smaller than $5 \mathrm{~mm}$ due to the limited spatial resolution of the PET/CTscanner and relatively low uptake of the agent in prostate cancer. In the restaging of patients with $\mathrm{BCR}$, choline PET has been more successful in patients with higher PSA ( $>4 \mathrm{ng} / \mathrm{mL}$ ), higher Gleason score, and CRPC [49]. However, it is hoped that PET agents could detect disease at an early state.

\section{Prostate-Specific Membrane Antigen (PSMA) Targeting PET Tracers}

PSMA is a transmembrane protein that is a highly specific marker for prostate cancer. Increased expression of PSMA is found in all prostate cancers, particularly in high grade, hormone-refractory, and metastatic disease [50]. As such, PSMA is an ideal target for detecting prostate cancer and several molecular imaging approaches targeting PSMA are currently being investigated. The initial focus of PSMA targeting was on radiolabeled monoclonal antibodies directed against the intracellular domain of PSMA. Indium ( $\left.{ }^{111} \mathrm{In}\right)$ capromab pendetide was approved by the Food and Drug Administration since 1996 as a gamma camera and/or SPECT agent (ProstaScint, Cytogen). Although PSMA is ubiquitous in the prostate, PSMA expression is normally low in normal prostate glandular epithelium as it is only found in the luminal cells of the gland but in cancer cells PSMA is found on the basal layer far more available for targeting with a PET agent. PSMA expression correlates with tumor grade and is significantly upregulated in androgen-independent prostate cancer. However, the target of capromab pendetide is intracellular, and thus, cell membranes must be disrupted to allow binding, which is an important limitation of this method. Anatomic localization of capromab pendetide uptake has been challenging because of its nonspecific binding and high blood pool activity. Moreover, SPECT imaging has inferior spatial resolution compared to PET (6-7 mm). Antibody imaging with capromab pendetide can detect lymph node metastases, recurrence after prostatectomy, and occult metastatic involvement; however, recurrences usually have to be quite large. Although techniques such as fusion with anatomic images and combined SPECT-CT improve the specificity of capromab pendetide antibody imaging, its overall accuracy is still low [51, 52]. Schettino et al. evaluated indium-111 Prosta-Scint SPECT scans in 58 patients with 161 positive sites of disease. False positives in 74 sites subsequently were due to bowel, vessel, or marrow activity. Twenty-five patients previously thought to have nodal disease appeared to have only local disease after fusion [52].

Several radiolabeled small molecules targeting the external domain of PSMA have been developed. The 2-PMPA analog (2S,4S)-2-[ $\left.{ }^{18} \mathrm{~F}\right]-$ fluoro-4 (phosphonomethyl) pentanedioid acid (BAY1075553) is one such tracer. Early studies have shown that this tracer is safe and well tolerated in human subjects and shows potential in detecting prostate cancer in patients with localized and advanced disease [53]. More recently, the $N-[N-[(S)-1,3-$ dicarboxypropyl] carbamoyl]-4- $\left[{ }^{18} \mathrm{~F}\right]$ fluorobenzyl-L-cysteine $\left({ }^{18} \mathrm{~F}-\mathrm{DCFBC}\right)$ was developed at Johns Hopkins University and allows for targeting the external domain of PSMA [54]. Early clinical studies have shown promising results and others are currently underway [NCT02190279] to determine the efficacy of ${ }^{18} \mathrm{~F}-\mathrm{DCFBC}$ in accurately identifying metastatic disease [55]. 
PSMA-binding agents have also been labeled with ${ }^{68} \mathrm{Ga}$, which can be radiolabeled on site using a chelate. Afshar et al. performed a retrospective analysis in 319 patients who underwent ${ }^{68} \mathrm{Ga}$-PSMA-ligand PET/CT for detection of recurrent PCa. Histological verification was performed in 42 patients after the ${ }^{68} \mathrm{Ga}$-PSMA-ligand PET/CT. In $82.8 \%$ of the patients, at least one lesion indicative of recurrent PCa was detected. Among lesions investigated by histology, 30 were false-negative in 4 different patients, and all other lesions $(n=416)$ were true-positive or true-negative. A lesion-based analysis of sensitivity, specificity, NPV, and PPV were 76.6, 100, 91.4, and $100 \%$, respectively. A patient-based analysis revealed a sensitivity of $88.1 \%$ [56].

\section{${ }^{18}$ F-fluoro-5a-dihydrotestosterone (FDHT)}

Androgen deprivation therapy (ADT) is an adjunct treatment for prostate cancer. The androgen receptor (AR) plays a major role in the pathogenesis of prostate cancer and it binds dihydrotestosterone (DHT) causing the translocation of the AR from the cytoplasm to the nucleus whereupon AR acts as a transcription factor. The agent ${ }^{18} \mathrm{~F}$-fluoro-5adihydrotestosterone $\left({ }^{18}\right.$ F-FDHT) created first at Washington University (St. Louis, MO) but most widely used at Memorial Sloan Kettering, is a labeled radiotracer analog of DHT [57]. The uptake of this radiotracer can be measured quantitatively and uptake correlates with the degree of AR expression [58]. This agent has not been extensively studied in nodal staging; however, a 2005 study by Dehdashti et al. included nodal detection on a per-patient basis [57]. CT identified nodal abnormalities in 14 of 19 cases (73.6\%) compared to only 8 of 19 cases $(42.1 \%)$ using ${ }^{18}$ F-FDHT PET. The validation techniques were limited in this study, since there was no reference standard other than conventional imaging for defining the extent of disease [57]. Thus, the status of ${ }^{18}$ F-FDHT PET as a lymph node imaging agent is still unclear.

\section{Anti-1-amino-3-18 F-fluorocyclobutane-1-carboxylic acid ( $\left.{ }^{18} \mathrm{~F}-\mathrm{FACBC}\right)$}

${ }^{18} \mathrm{~F}-\mathrm{FACBC}$ is an radiolabeled analog of leucine and has been shown to accumulate at sites of prostate cancer and local recurrence [59]. Early studies have shown encouraging results in the ability of ${ }^{18}$ F-FACBC to accurately stage cancer, with a reported increase of $20-40 \%$ in lesion detection versus the more commonly used ${ }^{18} \mathrm{~F}$-choline PET/CT technique [60]. Kairemo et al. reported the ability of ${ }^{18} \mathrm{~F}-\mathrm{FACBC}$ PET to assist in restaging prostate cancer, particularly in patients with short PSA doubling times. In 26 patients, ${ }^{18}$ F-FACBC PET identified 58 lesions, 19 of which $(32.7 \%)$ were in the lymph nodes. The mean serum PSA level in patients with positive ${ }^{18}$ F-FACBC PET findings was $9.5 \pm 16.9 \mu \mathrm{g} / \mathrm{L}(0.54-69 \mu \mathrm{g} / \mathrm{L})$ and in patients with negative ${ }^{18}$ F-FACBC PET findings was $1.96 \pm 1.87 \mu \mathrm{g} / \mathrm{L}(0.11-5.9 \mu \mathrm{g} / \mathrm{L})$, but the difference was not statistically significant. However, the PSA doubling time (PDT) in patients with positive findings was significantly shorter than the PDT in patients with negative findings: $3.25 \pm 2.09$ months (0.3-6 months) versus 31.2 \pm 22.02 months (8-84 months), $P<0.0001$ [61]. More research is warranted to determine the extent to which ${ }^{18} \mathrm{~F}$ FACBC PET can be utilized in the setting of staging nodal spread or in the treatment of recurrent prostate cancer. 


\section{${ }^{11}$ C-Acetate}

Acetate is a molecule that is converted to acetyl coenzyme A (acetyl-CoA) via fatty acid synthase (FAS) for use in lipid metabolism. Thus, acetate may be used by prostate cancer as a means of providing energy using fatty acid metabolism [62, 63•]. Various studies have shown the utility of ${ }^{11} \mathrm{C}$-acetate in the detection of primary prostate cancer, including nodal disease and bone metastases. Its short half-life of $20 \mathrm{~min}$, however, is its main limitation. Early studies by Oyama et al. (2002) and Fricke et al. (2003) showed a $60 \%$ increase in perpatient nodal detection with ${ }^{11} \mathrm{C}$-acetate when compared to FDG PET [64, 65]. Oyama et al. found no correlation between lesion uptake and serum PSA, whereas Fricke et al. reported a strong positive correlation between lesional tracer uptake and serum PSA [64, 65]. A more recent comprehensive study on ${ }^{11} \mathrm{C}$-acetate PET by Hasseebuddin et al. (2013) examined 107 patients in whom ${ }^{11} \mathrm{C}$-acetate PET/CT was performed prior to radical prostatectomy for the purpose of staging and predicting treatment failure [66]. The sensitivity, specificity, positive predictive value, and negative predictive value were reported to be 68.0, 78.1, 48.6, and $88.9 \%$, respectively. The ${ }^{11} \mathrm{C}$-acetate $\mathrm{PET} / \mathrm{CT}$ was positive in 36 of 107 patients, while histopathology confirmed nodal metastases in 25 patients (23.4\%) [66]. While further multiinstitutional studies are needed, this technique may provide more accurate information than conventional imaging for the initial treatment planning and surgical management of patients with moderate to aggressive prostate cancer.

\section{Conclusion}

Lymph node involvement is a crucial prognostic factor in prostate cancer. Currently, available routine imaging techniques such as $\mathrm{CT}$ and MRI are limited due to their dependence on size criteria resulting in their low sensitivity. There are novel imaging approaches for improving nodal staging of prostate cancer such as lymphotropic iron oxide particles and PET imaging with targeted radiotracers. Although results reported from several groups are promising in these approaches, further research is required to optimize these novel imaging techniques and implement them into standard clinical practice.

\section{References}

Papers of particular interest, published recently, have been highlighted as:

- Of importance

1. American Cancer Society. Cancer facts \& figures 2014 [Internet]. Atlanta; 2014 p. 19-20. Available from:http://www.cancer.org/acs/groups/content/@ research/documents/webcontent/ acspc-042151.pdf.

2. Bader P, Burkhard FC, Markwalder R, Studer UE. Disease progression and survival of patients with positive lymph nodes after radical prostatectomy. Is there a chance of cure? J Urol 2003;169:84954. [PubMed: 12576797]

3. Bastian PJ, Boorjian SA, Bossi A, Briganti A, Heidenreich A, Freedland SJ, et al. High-risk prostate cancer: from definition to contemporary management. Eur. Urol [Internet]. 2012 [cited 2014 Oct 24];61:1096-106. Available from: http://www.ncbi.nlm.nih.gov/pubmed/22386839. [PubMed: 22386839]

4. Daneshmand S, Quek ML, Stein JP, Lieskovsky G, Cai J, Pinski J, et al. Prognosis of patients with lymph node positive prostate cancer following radical prostatectomy: long-term results. J. Urol 
[Internet]. 2004 [cited 2014 Nov 14];172:2252-5. Available from: http://www.ncbi.nlm.nih.gov/ pubmed/15538242. [PubMed: 15538242]

5. Briganti A, Chun FK-H, Salonia A, Suardi N, Gallina A, Da Pozzo LF, et al. Complications and other surgical outcomes associated with extended pelvic lymphadenectomy in men with localized prostate cancer. Eur. Urol [Internet]. 2006 [cited 2014 Nov 14];50: 1006-13. Available from: http:// www.ncbi.nlm.nih.gov/pubmed/16959399. [PubMed: 16959399]

6. Saokar A, Islam T, Jantsch M, Saksena M a, Hahn PF, Harisinghani MG. Detection of lymph nodes in pelvic malignancies with computed tomography and magnetic resonance imaging. Clin. Imaging [Internet]. Elsevier Inc.; 2010 [cited 2014 Oct 30];34:361-6. Available from: http:// www.ncbi.nlm.nih.gov/pubmed/20813300. [PubMed: 20813300]

7. Mattei A, Danuser H. Contemporary imaging analyses of pelvic lymph nodes in the prostate cancer patient. Curr. Opin. Urol [Internet]. 2011 [cited 2014 Oct 30];21:211-8. Available from: http:// www.ncbi.nlm.nih.gov/pubmed/21311336. [PubMed: 21311336]

8. Jager GJ, Barentsz JO, Oosterhof GO, Witjes JA, Ruijs SJH. Pelvic adenopathy in prostatic and urinary bladder carcinoma: MR imaging with a three-dimensional TI-weighted magnetizationprepared-rapid gradient-echo. Am. J. Roentgenol [Internet]. 1996 [cited 2014 Oct 31];167:1503-7. Available from: http://www.ajronline.org/doi/abs/10.2214/ajr.167.6.8956585 [PubMed: 8956585]

9. Engeler C, Wasserman N, Zhang G. Preoperative assessment of prostatic carcinoma by computerized tomography: weaknesses and new perspectives. Urology 1992; 40:346-50. Available from: http://www.sciencedirect.com/science/article/pii/009042959290386B. [PubMed: 1413354]

10. Perrotti M, Kaufman RP, Jennings TA, Thaler HT, Soloway SM, Rifkin MD, et al. Endo-rectal coil magnetic resonance imaging in clinically localized prostate cancer: is it accurate? J. Urol [Internet]. 1996;156:106-9. Available from: http://linkinghub.elsevier.com/retrieve/pii/ S002253470165955X. [PubMed: 8648768]

11. Lecouvet FE, El Mouedden J, Collette L, Coche E, Danse E, Jamar F, et al. Can whole-body magnetic resonance imaging with diffusion-weighted imaging replace Tc $99 \mathrm{~m}$ bone scanning and computed tomography for single-step detection of metastases in patients with high-risk prostate cancer? Eur. Urol [Internet]. 2012 [cited 2014 Oct 30];62:68-75. Available from: http:// www.ncbi.nlm.nih.gov/pubmed/22366187. [PubMed: 22366187]

12. Eisenhauer E a, Therasse P, Bogaerts J, Schwartz LH, Sargent D, Ford R, et al. New response evaluation criteria in solid tumours: revised RECIST guideline (version 1.1). Eur. J. Cancer [Internet]. Elsevier Ltd; 2009 [cited 2014 Jul 10];45:228-47. Available from: http:// www.ncbi.nlm.nih.gov/pubmed/19097774. [PubMed: 19097774]

13. Anzai Y, Piccoli C, Outwater E. Evaluation of neck and body metastases to nodes with ferumoxtran 10-enhanced MR imaging: phase III safety and efficacy study 1. Radiology 2003;228:777-88. doi: 10.1148/radiol.2283020872. [PubMed: 12954896]

14. Budiharto T, Joniau S, Lerut E, Van den Bergh L, Mottaghy F, Deroose CM, et al. Prospective evaluation of 11C-choline positron emission tomography/computed tomography and diffusionweighted magnetic resonance imaging for the nodal staging of prostate cancer with a high risk of lymph node metastases. Eur. Urol [Internet]. 2011 [cited 2014 Oct 30];60:125-30. Available from: http://www.ncbi.nlm.nih.gov/pubmed/21292388. [PubMed: 21292388]

15. Hövels A, Heesakkers R, Adang E, Jager G, Strum S, Hoogeveen Y, et al. The diagnostic accuracy of CT and MRI in the staging of pelvic lymph nodes in patients with prostate cancer: a metaanalysis. Clin. Radiol [Internet]. 2008 [cited 2014 Oct 20];63:387-95. Available from: http:// www.ncbi.nlm.nih.gov/pubmed/18325358 [PubMed: 18325358]

16. Heidenreich A, Aus G, Bolla M, Joniau S, Matveev VB, Schmid HP, et al. EAU guidelines on prostate cancer. Eur. Urol [Internet]. 2008 [cited 2014 Sep 17];53:68-80. Available from: http:// www.ncbi.nlm.nih.gov/pubmed/17920184. [PubMed: 17920184]

17. Tabatabaei S, Saylor PJ, Coen J, Dahl DM. Prostate cancer imaging: what surgeons, radiation oncologists, and medical oncologists want to know. AJR. Am. J. Roentgenol [Internet]. 2011 [cited 2014 Oct 30];196:1263-6. Available from: http://www.ncbi.nlm.nih.gov/pubmed/21606287. [PubMed: 21606287]

18. Borley N, Fabrin K, Sriprasad S, Mondaini N, Thompson P, Muir G, et al. Laparoscopic pelvic lymph node dissection allows significantly more accurate staging in "high-risk" prostate cancer 
compared to MRI or CT. Scand. J. Urol. Nephrol [Internet]. 2003 [cited 2014 Oct 31];37:382-6. Available from: http://www.ncbi.nlm.nih.gov/pubmed/14594685. [PubMed: 14594685]

19. Dooms G, Hricak H, Crooks L, Higgins C. Magnetic resonance imaging of the lymph nodes: comparison with CT. Radiology 1984;153:719-28. doi:10.1148/radiology.153.3.6093190. [PubMed: 6093190]

20. Yang W, Lam W. Comparison of dynamic helical CT and dynamic MR imaging in the evaluation of pelvic lymph nodes in cervical carcinoma. Am J 2000;175:759-66. doi:10.2214/ajr. 175.3.1750759.

21. Brown G, Richards C, Bourne M. Morphologic predictors of lymph node status in rectal cancer with use of high-spatial-resolution MR imaging with histopathologic comparison 1. Radiology [Internet]. 2003 [cited 2014 Oct 31];227:371-7. Available from: http://pubs.rsna.org/doi/abs/ 10.1148/radiol.2272011747. [PubMed: 12732695]

22. Kim JH, Beets GL, Kim M-J, Kessels AGH, Beets-Tan RGH. High-resolution MR imaging for nodal staging in rectal cancer: are there any criteria in addition to the size? Eur. J. Radiol [Internet]. 2004 [cited 2014 Oct 31];52:78-83. Available from: http://www.ncbi.nlm.nih.gov/ pubmed/15380850. [PubMed: 15380850]

23. Thoeny HC, Froehlich JM, Triantafyllou M, Huesler J, Bains LJ, Vermathen P, et al. Metastases in normal-sized pelvic lymph nodes: detection with diffusion-weighted MR imaging. Radiology [Internet]. 2014 [cited 2014 Dec 14];273:125-35. Available from: http://www.ncbi.nlm.nih.gov/ pubmed/24893049. [PubMed: 24893049]

24•. Harisinghani MG, Barentsz J, Hahn PF, Deserno WM, Tabatabaei S, van de Kaa CH, et al. Noninvasive detection of clinically occult lymph-node metastases in prostate cancer. N. Engl. J. Med 2003;348:2491-9. [PubMed: 12815134] One of the largest series on iron oxide enhanced MR for lymph node staging of prostate cancer.

25. Harisinghani MG, Saini S, Weissleder R, Hahn PF, Yantiss RK, Tempany C, et al. MR lymphangiography using ultrasmall superparamagnetic iron oxide in patients with primary abdominal and pelvic malignancies: radiographic-pathologic correlation. AJR. Am. J. Roentgenol [Internet]. 1999 [cited 2014 Nov 7];172:1347-51. Available from: http://www.ncbi.nlm.nih.gov/ pubmed/10227514. [PubMed: 10227514]

26. Barentsz JO, Fütterer JJ, Takahashi S. Use of ultrasmall superparamagnetic iron oxide in lymph node MR imaging in prostate cancer patients. Eur J Radiol 2007;63:369-72. [PubMed: 17689215]

27. Islam T, Wolf $\mathrm{G}$. The pharmacokinetics of the lymphotropic nano-particle MRI contrast agent ferumoxtran-10. Cancer Biomarkers 2009;5:69-73. [PubMed: 19414923]

28. Triantafyllou M, Studer UE, Birkhäuser FD, Fleischmann A, Bains LJ, Petralia G, et al. Ultrasmall superparamagnetic particles of iron oxide allow for the detection of metastases in normal sized pelvic lymph nodes of patients with bladder and/or prostate cancer. Eur. J. Cancer [Internet]. 2013 [cited 2014 Nov 14];49:616-24. Available from: http://www.ncbi.nlm.nih.gov/pubmed/23084842. [PubMed: 23084842]

29. Birkhäuser FD, Studer UE, Froehlich JM, Triantafyllou M, Bains LJ, Petralia G, et al. Combined ultrasmall superparamagnetic particles of iron oxide-enhanced and diffusion-weighted magnetic resonance imaging facilitates detection of metastases in normal-sized pelvic lymph nodes of patients with bladder and prostate cancer. Eur Urol 2013;64:953-60. [PubMed: 23916692]

30. Heesakkers RAM, Fütterer JJ, Hövels AM, van den Bosch HCM, Scheenen TWJ, Hoogeveen YL, et al. Prostate cancer evaluated with ferumoxtran-10-enhanced T2*-weighted MR imaging at 1.5 and 3.0 T: early experience. Radiology 2006;239:481-7. [PubMed: 16641354]

31. Fortuin AS, Deserno WMLLG, Meijer HJM, Jager GJ, Takahashi S, Debats OAet al. Value of PET/CT and MR lymphography in treatment of prostate cancer patients with lymph node metastases. Int J Radiat Oncol, Biol, Phys 2012;84:712-8. [PubMed: 22417806]

32. Anzai Y Superparamagnetic iron oxide nanoparticles: nodal metastases and beyond. Top Magn Reson Imaging 2004;15:103-11. Available from www.ncbi.nlm.nih.gov/pubmed/15269613 [PubMed: 15269613]

33. Bashir MR, Bhatti L, Marin D, Nelson RC. Emerging applications for ferumoxytol as a contrast agent in MRI. J. Magn. Reson. Imaging [Internet]. 2014 [cited 2014 Nov 7]; Available from: http:// www.ncbi.nlm.nih.gov/pubmed/24974785. 
34. Landry R, Jacobs PM, Davis R, Shenouda M, Bolton WK. Pharmacokinetic study of ferumoxytol: a new iron replacement therapy in normal subjects and hemodialysis patients. Am. J. Nephrol [Internet]. [cited 2014 Nov 14];25:400-10. Available from: http://www.ncbi.nlm.nih.gov/pubmed/ 16088081.

35. Spinowitz BS, Schwenk MH, Jacobs PM, Bolton WK, Kaplan MR, Charytan C, et al. The safety and efficacy of ferumoxytol therapy in anemic chronic kidney disease patients. Kidney Int [Internet]. 2005 [cited 2014 Nov 14];68:1801-7. Available from: http://www.ncbi.nlm.nih.gov/ pubmed/16164657. [PubMed: 16164657]

36. Provenzano R, Schiller B, Rao M, Coyne D, Brenner L, Pereira BJG. Ferumoxytol as an intravenous iron replacement therapy in hemodialysis patients. Clin. J. Am. Soc. Nephrol [Internet]. 2009 [cited 2014 Nov 14];4:386-93. Available from: http:// www.pubmedcentral.nih.gov/articlerender.fcgi? artid $=2637590 \&$ tool $=$ pmcentre $\&$ rendertype $=$ abstract.

37. Harisinghani M, Ross RW, Guimaraes AR, Weissleder R. Utility of a new bolus-injectable nanoparticle for clinical cancer staging. Neoplasia [Internet]. 2007 [cited 2014 Nov 14];9:1160-5. Available from: http://www.pubmedcentral.nih.gov/articlerender.fcgi? artid=2134912\&tool=pmcentrez\&rendertype=abstract. [PubMed: 18084623]

38. Turkbey B. A phase I dosing study of ferumoxytol for magnetic resonance lymphography at 3 Tesla in patients with prostate cancer.

39. U.S. Food and Drug Administration. FDA approved drug products: Feraheme ${ }^{\mathrm{TM}}$ (ferumoxytol) injection [Internet]. 2009 Available from: http://www.accessdata.fda.gov/drugsatfda_docs/label/ 2009/022180lbl.pdf.

40. Auerbach M, Strauss W, Auerbach S, Rineer S, Bahrain H. Safety and efficacy of total dose infusion of 1,020 mg of ferumoxytol administered over $15 \mathrm{~min}$. Am. J. Hematol [Internet]. 2013 [cited 2014 Dec 14];88:944-7. Available from: http://www.ncbi.nlm.nih.gov/pubmed/23828252. [PubMed: 23828252]

41. Beheshti M, Imamovic L, Broinger G, Vali R, Waldenberger P, Stoiber F, et al. 18F-choline $\mathrm{PET} / \mathrm{CT}$ in the preoperative staging of prostate cancer in patients with intermediate or high risk of extracapsular disease: a prospective study of 130 patients. Radiology [Internet]. 2010 [cited 2014 Nov 14];254:925-33. Available from: http://www.ncbi.nlm.nih.gov/pubmed/20177103. [PubMed: 20177103]

42. Stewart GD, Gray K, Pennington CJ, Edwards DR, Riddick ACP, Ross JA, et al. Analysis of hypoxia-associated gene expression in prostate cancer: lysyl oxidase and glucose transporter-1 expression correlate with Gleason score. Oncol. Rep [Internet]. 2008 [cited 2014 Nov 14]; 20:1561-7. Available from: http://www.ncbi.nlm.nih.gov/pubmed/19020742. [PubMed: 19020742]

43. Shreve PD, Grossman HB, Gross MD, Wahl RL. Metastatic prostate cancer: initial findings of PET with 2-deoxy-2-[F-18]fluoro-D-glucose. Radiology [Internet]. 1996 [cited 2014 Nov 14];199:7516. Available from: http://www.ncbi.nlm.nih.gov/pubmed/8638000. [PubMed: 8638000]

44. Schöder H, Herrmann K, Gönen M, Hricak H, Eberhard S, Scardino P, et al. 2-[18F]fluoro-2deoxyglucose positron emission tomography for the detection of disease in patients with prostatespecific antigen relapse after radical prostatectomy. Clin. Cancer Res [Internet]. 2005 [cited 2014 Nov 14];11:4761-9. Available from: http://www.ncbi.nlm.nih.gov/pubmed/16000572. [PubMed: 16000572]

45. Kao P-F, Chou Y-H, Lai C-W. Diffuse FDG uptake in acute prostatitis. Clin. Nucl. Med [Internet]. 2008 [cited 2014 Nov 14];33: 308-10. Available from: http://www.ncbi.nlm.nih.gov/pubmed/ 18356681. [PubMed: 18356681]

46. Kotzerke J, Prang J, Neumaier B, Volkmer B, Guhlmann A, Kleinschmidt K, et al. Experience with carbon-11 choline positron emission tomography in prostate carcinoma. Eur. J. Nucl. Med [Internet]. 2000 [cited 2014 Nov 14];27:1415-9. Available from: http://www.ncbi.nlm.nih.gov/ pubmed/11007527. [PubMed: 11007527]

47. Tilki D, Reich O, Graser A, Hacker M, Silchinger J, Becker AJ, et al. 18F-fluoroethylcholine $\mathrm{PET} / \mathrm{CT}$ identifies lymph node metastasis in patients with prostate-specific antigen failure after radical prostatectomy but underestimates its extent. Eur. Urol [Internet]. 2013 [cited 2014 Nov 14]; 63:792-6. Available from: http://www.ncbi.nlm.nih.gov/pubmed/22902037. [PubMed: 22902037] 
48•. Evangelista L, Guttilla A, Zattoni F, Muzzio PC, Zattoni F. Utility of choline positron emission tomography/computed tomography for lymph node involvement identification in intermediate-to high-risk prostate cancer: a systematic literature review and meta-analysis. Eur. Urol [Internet]. 2013 [cited 2014 Nov 3];63:1040-8. Available from: http://www.ncbi.nlm.nih.gov/pubmed/ 23036576. [PubMed: 23036576] A detailed review and meta-analysis of choline PET/CT for nodal staging of prostate cancer.

49. Evangelista L, Zattoni F, Guttilla A, Saladini G, Zattoni F, Colletti PM, et al. Choline PET or PET/CT and biochemical relapse of prostate cancer: a systematic review and meta-analysis. Clin. Nucl. Med [Internet]. 2013 [cited 2014 Nov 14];38:305-14. Available from: http:// www.ncbi.nlm.nih.gov/pubmed/23486334. [PubMed: 23486334]

50. Wright GL, Haley C, Beckett ML, Schellhammer PF. Expression of prostate-specific membrane antigen in normal, benign, and malignant prostate tissues. Urol. Oncol [Internet]. [cited 2014 Nov 14];1: 18-28. Available from: http://www.ncbi.nlm.nih.gov/pubmed/21224086.

51. Hinkle GH, Burgers JK, Olsen JO, Williams BS, Lamatrice RA, Barth RF, et al. Prostate cancer abdominal metastases detected with indium-111 capromab pendetide. J. Nucl. Med [Internet]. 1998 [cited 2014 Nov 14];39:650-2. Available from: http://www.ncbi.nlm.nih.gov/pubmed/ 9544673. [PubMed: 9544673]

52. Schettino CJ, Kramer EL, Noz ME, Taneja S, Padmanabhan P, Lepor H. Impact of fusion of indium-111 capromab pendetide volume data sets with those from MRI or CT in patients with recurrent prostate cancer. AJR. Am. J. Roentgenol [Internet]. 2004 [cited 2014 Nov 14];183:519_ 24. Available from: http://www.ncbi.nlm.nih.gov/pubmed/15269050 [PubMed: 15269050]

53. Beheshti M, Kunit T, Haim S, Zakavi R, Schiller C, Stephens A, et al. BAY 1075553 PET-CT for staging and restaging prostate cancer patients: comparison with [(18)F] fluorocholine PET-CT (phase I study). Mol. Imaging Biol [Internet]. 2014 [cited 2014 Nov 14]; Available from: http:// www.ncbi.nlm.nih.gov/pubmed/25315836.

54. Mease RC, Foss CA, Pomper MG. PET imaging in prostate cancer: focus on prostate-specific membrane antigen. Curr. Top. Med. Chem [Internet]. 2013 [cited 2014 Nov 14];13:951-62. Available from: http://www.pubmedcentral.nih.gov/articlerender.fcgi? $\operatorname{artid}=4067736 \&$ tool $=$ pmcentrez $\&$ rendertype $=$ abstract. [PubMed: 23590171 ]

55. 18F-DCFBC PET/CT in prostate cancer [Internet]. Natl. Cancer Inst 2014 Available from: http:// clinicaltrials.gov/show/NCT02190279.

56. Afshar-Oromieh A, Avtzi E, Giesel FL, Holland-Letz T, Linhart HG, Eder M, et al. The diagnostic value of PET/CT imaging with the (68)Ga-labelled PSMA ligand HBED-CC in the diagnosis of recurrent prostate cancer. Eur. J. Nucl. Med. Mol. Imaging [Internet]. 2014 [cited 2014 Dec 14]; Available from: http://www.ncbi.nlm.nih.gov/pubmed/25411132.

57. Dehdashti F, Picus J, Michalski JM, Dence CS, Siegel BA, Katzenellenbogen JA, et al. Positron tomographic assessment of androgen receptors in prostatic carcinoma. Eur. J. Nucl. Med. Mol. Imaging [Internet]. 2005 [cited 2014 Nov 14];32:344-50. Available from: http:// www.ncbi.nlm.nih.gov/pubmed/15726353 [PubMed: 15726353]

58. Beattie BJ, Smith-Jones PM, Jhanwar YS, Schöder H, Schmidtlein CR, Morris MJ, et al. Pharmacokinetic assessment of the uptake of 16beta-18F-fluoro-5alpha-dihydrotestosterone (FDHT) in prostate tumors as measured by PET. J. Nucl. Med [Internet]. 2010 [cited 2014 Nov 1]; 51:183-92. Available from: http://www.pubmedcentral.nih.gov/articlerender.fcgi? artid=2866076\&tool=pmcentrez\&rendertype=abstract. [PubMed: 20080885]

59. Schuster DM, Votaw JR, Nieh PT, Yu W, Nye JA, Master V, et al. Initial experience with the radiotracer anti-1-amino-3-18F-fluorocyclobutane-1-carboxylic acid with PET/CT in prostate carcinoma. J. Nucl. Med [Internet]. 2007 [cited 2014 Nov 14];48:56-63. Available from: http:// www.ncbi.nlm.nih.gov/pubmed/17204699. [PubMed: 17204699]

60. Nanni C, Schiavina R, Boschi S, Ambrosini V, Pettinato C, Brunocilla E, et al. Comparison of 18FFACBC and 11C-choline PET/CT in patients with radically treated prostate cancer and biochemical relapse: preliminary results. Eur. J. Nucl. Med. Mol. Imaging [Internet]. 2013 [cited 2014 Nov 14];40 Suppl 1:S11-7. Available from: http://www.ncbi.nlm.nih.gov/pubmed/23591953. [PubMed: 23591953]

61. Kairemo K, Rasulova N, Partanen K, Joensuu T. Preliminary clinical experience of trans-1amino-3-(18)F-fluorocyclobutanecarboxylic acid (anti-(18)F-FACBC) PET/CT imaging in prostate 
cancer patients. Biomed Res. Int [Internet]. 2014 [cited 2014 Nov 14];2014:305182 Available from: http://www.pubmedcentral.nih.gov/articlerender.fcgi?

artid=4058669\&tool=pmcentrez\&rendertype=abstract [PubMed: 24991547]

62. Liu Y Fatty acid oxidation is a dominant bioenergetic pathway in prostate cancer. Prostate Cancer Prostatic Dis [Internet]. 2006 [cited 2014 Nov 14];9:230-4. Available from: http:// www.ncbi.nlm.nih.gov/pubmed/16683009. [PubMed: 16683009]

63. Apolo AB, Pandit-Taskar N, Morris MJ. Novel tracers and their development for the imaging of metastatic prostate cancer. J. Nucl. Med [Internet]. 2008 [cited 2014 Nov 14];49:2031-41. Available from: http://www.pubmedcentral.nih.gov/articlerender.fcgi? artid=3310891\&tool=pmcentrez \&rendertype=abstract. [PubMed: 18997047] A comprehensive review on novel PET tracers for iamging of prostate cancer metastases

64. Oyama N, Akino H, Kanamaru H, Suzuki Y, Muramoto S, Yonekura Y, et al. 11C-acetate PET imaging of prostate cancer. J. Nucl. Med [Internet]. 2002 [cited 2014 Nov 14];43:181-6. Available from: http://www.ncbi.nlm.nih.gov/pubmed/11850482. [PubMed: 11850482]

65. Fricke E, Machtens S, Hofmann M, van den Hoff J, Bergh S, Brunkhorst T, et al. Positron emission tomography with $11 \mathrm{C}$-acetate and $18 \mathrm{~F}-\mathrm{FDG}$ in prostate cancer patients. Eur. J. Nucl. Med. Mol. Imaging [Internet]. 2003 [cited 2014 Nov 14];30:607-11. Available from: http:// www.ncbi.nlm.nih.gov/pubmed/12589476. [PubMed: 12589476]

66. Haseebuddin M, Dehdashti F, Siegel BA, Liu J, Roth EB, Nepple KG, et al. 11C-acetate PET/CT before radical prostatectomy: nodal staging and treatment failure prediction. J. Nucl. Med [Internet]. 2013 [cited 2014 Nov 14];54:699-706. Available from: http:// www.pubmedcentral.nih.gov/articlerender.fcgi? artid=3787881\&tool=pmcentrez\&rendertype=abstract [PubMed: 23471311$]$ 


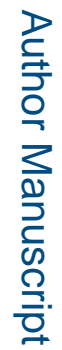

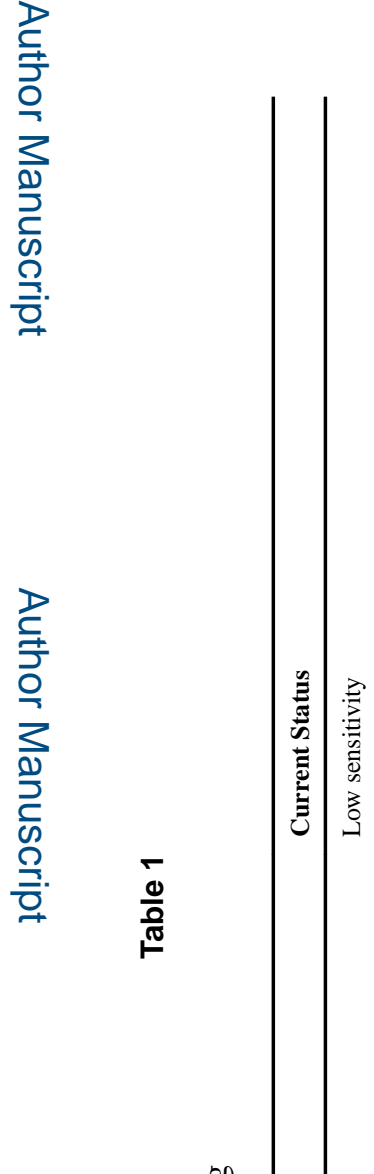


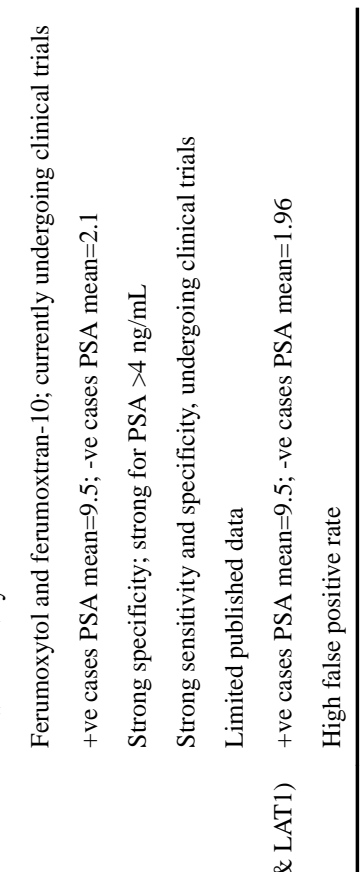

焉

골

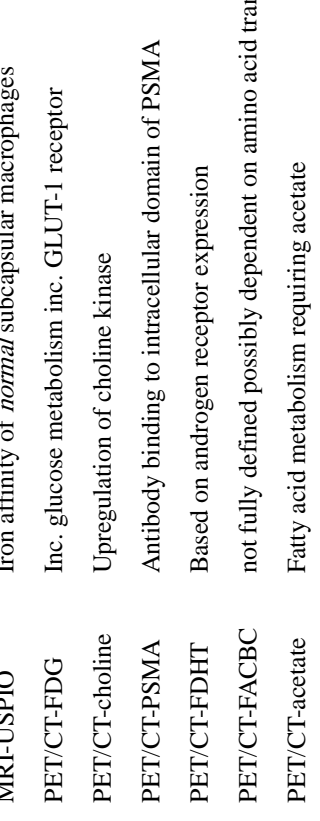

Curr Urol Rep. Author manuscript; available in PMC 2019 January 12. 